
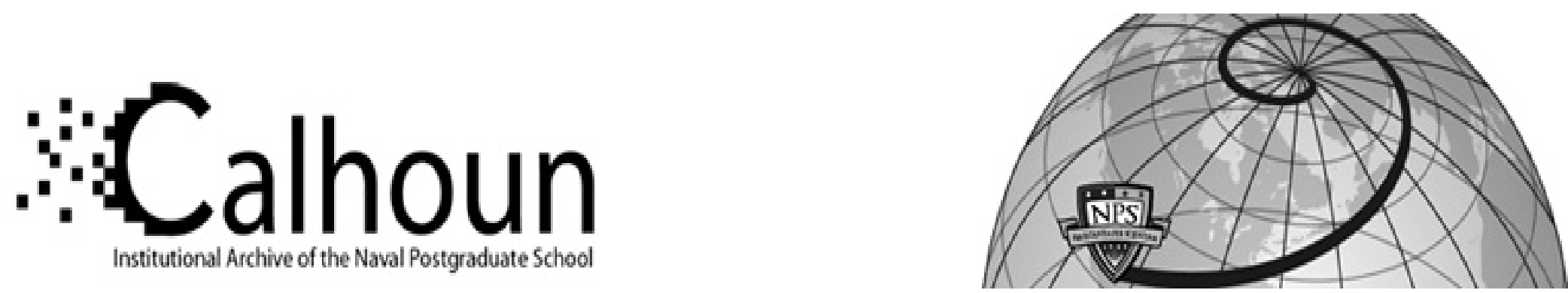

Calhoun: The NPS Institutional Archive DSpace Repository

Aerosol and Cloud Microphysical

Characteristics of Rifts and Gradients in Maritime Stratocumulus Clouds, 2006

Sharon, Tarah M.; Albrecht, Bruce A.; Jonsson, Haflidi H.;

Minnis, Patrick; Khaiyer, Mandana M.; van Reken, Timothy

M.; Seinfeld, John; Flagan, Rick

https://hdl.handle.net/10945/42207

This publication is a work of the U.S. Government as defined in Title 17, United States Code, Section 101. Copyright protection is not available for this work in the United States.

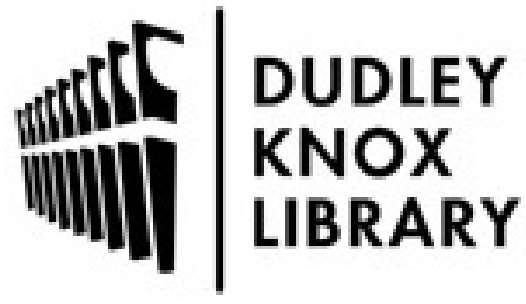

http://www.nps.edu/library
Calhoun is the Naval Postgraduate School's public access digital repository for research materials and institutional publications created by the NPS community. Calhoun is named for Professor of Mathematics Guy K. Calhoun, NPS's first appointed -- and published -- scholarly author.

Dudley Knox Library / Naval Postgraduate School 411 Dyer Road / 1 University Circle Monterey, California USA 93943 


\title{
Aerosol and Cloud Microphysical Characteristics of Rifts and Gradients in Maritime Stratocumulus Clouds
}

\author{
Tarah M. Sharon, ${ }^{*}$ Bruce A. Albrecht, ${ }^{*}$ Haflidi H. Jonsson, ${ }^{+}$Patrick Minnis, ${ }^{*}$ \\ Mandana M. Khaiyer, ${ }^{\circledR}$ Timothy M. van Reken, \& John SEInfeld, ** and Rick Flagan** \\ *Division of Meteorology and Physical Oceanography, Rosenstiel School of Marine and Atmospheric Science, University of Miami, \\ Miami, Florida \\ + Center for Interdisciplinary Remotely Piloted Aircraft Studies, Marina, California \\ \# Science Directorate, NASA Langley Research Center, Hampton, Virginia \\ @AS\&M, Inc., Hampton, Virginia \\ \& National Center for Atmospheric Research, Boulder, Colorado \\ ** California Institute of Technology, Pasadena, California
}

(Manuscript received 20 April 2004, in final form 28 July 2005)

\begin{abstract}
A cloud rift is characterized as a large-scale, persistent area of broken, low-reflectivity stratocumulus clouds usually surrounded by a solid deck of stratocumulus. A rift observed off the coast of California was investigated using an instrumented aircraft to compare the aerosol, cloud microphysical, and thermodynamic properties in the rift with those of the surrounding solid stratocumulus deck. The microphysical characteristics in the solid stratocumulus deck differ substantially from those of a broken, cellular rift where cloud droplet concentrations are a factor of 2 lower than those in the solid cloud. Furthermore, cloud condensation nuclei (CCN) concentrations were found to be about 3 times greater in the solid-cloud area compared with those in the rift. Although drizzle was observed near cloud top in parts of the solid stratocumulus cloud, the largest drizzle rates were associated with the broken clouds within the rift area and with extremely large effective droplet sizes retrieved from satellite data. Minimal thermodynamic differences between the rift and solid cloud deck were observed. In addition to marked differences in particle concentrations, evidence of a mesoscale circulation near the solid cloud-rift boundary is presented. This mesoscale circulation may provide a mechanism for maintaining a rift, but further study is required to understand the initiation of a rift and the conditions that may cause it to fill. A review of results from previous studies indicates similar microphysical characteristics in rift features sampled serendipitously. These observations indicate that cloud rifts are depleted of aerosols through the cleansing associated with drizzle and are a manifestation of natural processes occurring in marine stratocumulus.
\end{abstract}

\section{Introduction and background}

Stratocumulus clouds play a critical role in the earth's climate system due to their spatial and temporal extent; stratus-type clouds are observed over large fractions of the earth's ocean surface for most of the year (e.g., Klein et al. 1995). Stratocumulus decks off the coasts of California and other parts of the world, mainly off the western boundaries of major continents, have been

Corresponding author address: Bruce A. Albrecht, Division of Meteorology and Physical Oceanography, Rosenstiel School of Marine and Atmospheric Science, University of Miami, 4600 Rickenbacker Causeway, Miami, FL 33149.

E-mail: balbrecht@rsmas.miami.edu studied to better understand processes responsible for maintenance of these cloud systems. Although they cover extensive areas, on a given day, there can be large- and mesoscale variations in the characteristics of the clouds that are clearly visible from satellite images. For example, in Fig. 1a a rift area observed off the coast of California has an albedo that is substantially less than the surrounding solid stratocumulus deck. Although no formal definition exists, rifts are areas of low reflectivity that can be seen in satellite images of some stratocumulus decks. These regions appear as broken cloud areas usually surrounded by more solid stratocumulus clouds. Rifts are often associated with distinctly cellular conditions (Stevens et al. 2005), have lifetimes of days, and advect with the boundary layer winds. In 


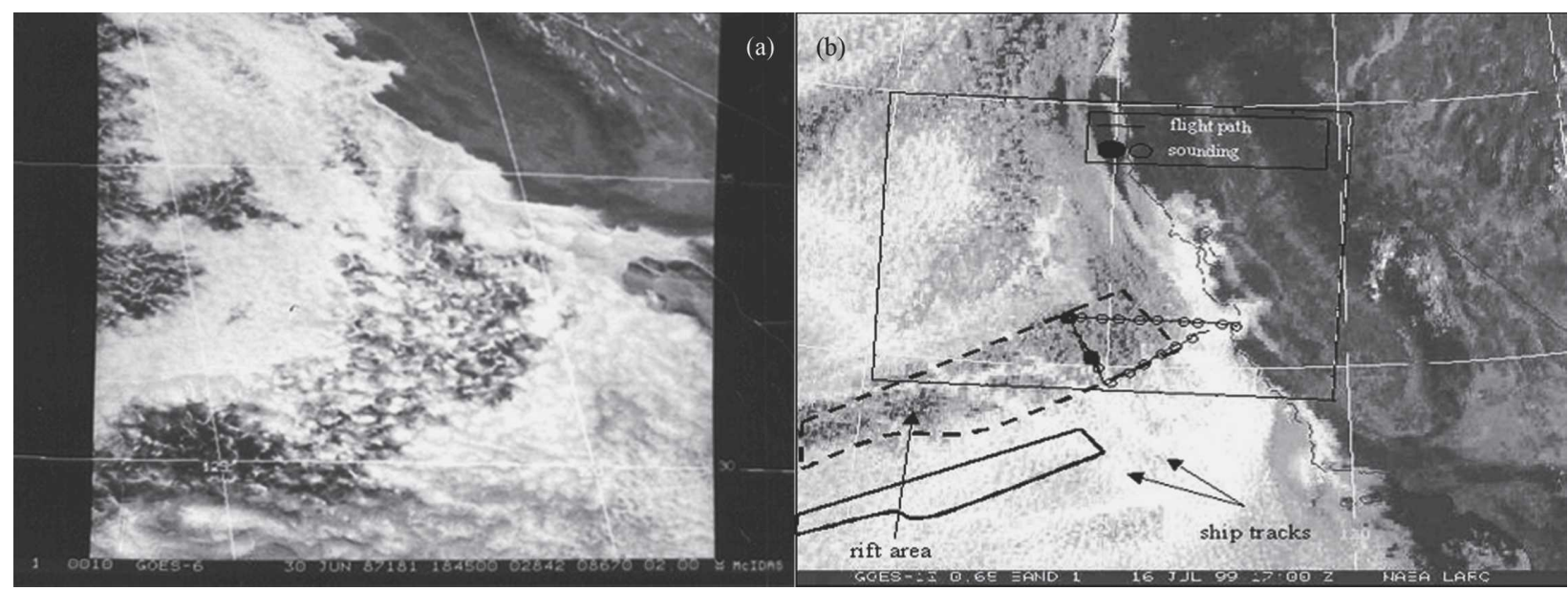

FIG. 1. (a) GOES-10 satellite image of stratocumulus clouds and embedded rift observed off the coast of California, 1845 UTC 30 Jun 1987. (b) GOES-10 visible satellite image of stratocumulus clouds and embedded rift observed off the coast of California, 1700 UTC $16 \mathrm{Jul} 1999$ with progression of the rift shown by the dashed line (corresponds to 1700 UTC) and solid thick line (corresponds to 2300 UTC). The flight path is also overlaid to identify location of soundings and path of aircraft. The circles indicate the location of the soundings taken during the flight (the open circles were not analyzed in detail in this study, the solid circles indicate the three soundings analyzed in detail; the two circles in the rift area almost overlap completely, appearing as only one circle).

another case shown in Fig. 1b, there is a strong enhancement of the reflectivity associated with ship tracks extending through a rift area observed just west of Monterey Bay, California. Since rifts appear in areas where sea surface, wind, and temperature conditions are similar to the adjacent solid clouds, they provide a unique opportunity for studying the processes that affect cloud structure.

The natural differences in aerosols and cloud condensation nuclei $(\mathrm{CCN})$ concentrations between marine and continental air can result in substantial variability in cloud characteristics. Drop size spectra associated with marine air, for example, has a much broader distribution than the spectra associated with continental air (Hudson and Yum 1997). The effects of aerosols on the properties of stratocumulus clouds can play a role in climate variability as well. Aerosols are the main source of particles on which cloud and fog droplets condense, affecting solar radiation both directly and indirectly through their influence on cloud albedo (Hoppel et al. 1990). Although not fully quantified, the indirect effects of aerosols on climate include altering cloud albedo (Twomey 1977) and changing cloud lifetime through precipitation efficiency (Albrecht 1989). Cloud albedo is critical to the first indirect effect where, for a given liquid water content, a cloud with smaller, more numerous droplets has a higher albedo than one with larger but fewer droplets (Twomey 1974). Furthermore, modification of the droplet spectra by aerosol variations can in turn alter precipitation processes in the cloud and thus affect cloud fraction (Al- brecht 1989) through the second indirect effect. Both processes result in a decrease in solar radiation at the surface of the earth associated with an increase in aerosols.

Aerosols do not independently affect the microphysical characteristics of clouds since precipitation processes can influence aerosol concentrations that can further affect the microphysics of the clouds. For example, in precipitating boundary layer clouds, CCN spectra can be modified by collision and coalescence processes associated with drizzle, even if drizzle droplets do not reach the surface. One possible explanation for the presence of large-scale, low-reflectivity, broken cloud areas (rifts) is that $\mathrm{CCN}$ concentrations may be reduced relative to those in the surrounding cloud and these lower CCN concentrations may moderate reflectivity and the cloud amount due to enhanced precipitation processes (Albrecht 1989).

The features shown in Fig. 1 depict the effects that rifts and ship tracks may have on the stratocumulus cloud regions. Rift regions encompassing broken cloud areas within a stratocumulus deck display a lower albedo than the adjacent solid stratocumulus clouds. Ship tracks such as those shown in Fig. 1, however, exhibit enhanced reflectivity relative to the surrounding clouds (Durkee et al. 2000a,b) due to increased aerosols originating from ship exhaust (first indirect effect) and a reduction in drizzle (Ferek et al. 2000) (second indirect effect). Upon close inspection of the gradient area shown in Fig. 1b, several ship tracks are seen to traverse the rift, two of which extend northwest to southeast and 
are crossed by a third trail extending almost east to west.

Rifts may also be good indicators of feedbacks between drizzle and observed cloud structure. If $\mathrm{CCN}$ concentrations increase, clouds become more optically thick as the collision and coalescence of cloud droplets is reduced, and the probability of precipitation production decreases. This situation is consistent with areas of cloud enhancement along ship tracks shown in Fig. 1b; where a smaller mean droplet size is observed (Albrecht 1989). Hence, once drizzle begins-although the mechanism for initiation is not fully known- $\mathrm{CCN}$ spectra are modified. This cleansing process may lead to an optically less reflective area in which cloud lifetime decreases due to enhanced drizzle (Albrecht 1989). If this process is operating, the cleansing process helps establish conditions that further support drizzle formation (Hegg 1999). Thus, one explanation of how a rift could be maintained is through this feedback. Several observations support this microphysical explanation (Stevens et al. 2005; van Zanten and Stevens 2005; Petters et al. 2006), although dynamics cannot be totally separated from the microphysical properties of clouds.

Visually, rifts and gradients seem to be advected by winds associated with the large-scale dynamics of the surrounding regions; therefore, their irregular shape and appearance cannot be fully explained by the synoptic-scale features present in the surrounding area. From a subjective analysis of satellite images of rift and gradient areas, rifts, when present, appear to encompass as many as $40 \%$ of the large cloud areas over the eastern Pacific on average. In addition, some rifts appear as patchy areas of broken clouds, but they can also be thousands of kilometers long and extend, in some cases, across the entire eastern Pacific Ocean basin. Usually rifts do not consist of completely clear air, but rather appear as areas of patchy, broken clouds, which have a cellular structure on the order of $10-20 \mathrm{~km}$; these features will be referred to as mesoscale. Variations in cloud characteristics associated with rifts and the surrounding cloud areas provide laboratory-type conditions for studying processes responsible for affecting cloud characteristics.

By comparing and contrasting the physical and thermodynamic properties of low albedo cloud areas of rifts with stratocumulus clouds and ship tracks, it is hoped that theories applied to ship track formation can be analogously applied and tested using observations of rifts. One major difference between ship tracks and rifts, however, lies in the origins of each phenomenon. Ship tracks occur when increased emission of particles in the area of a ship plume leads to an increase in concentration of $\mathrm{CCN}$ and thus enhances the reflectivity of the ship plume and the resulting "ship track" is visible on satellite imagery (Hobbs et al. 2000; Durkee et al. 2000a,b; Ferek et al. 2000). Indeed, ships that produce more aerosols produce tracks that are brighter, wider, and longer lived than those produced by ships that generate fewer aerosols (Durkee et al. 2000a,b). Thus, ship tracks are produced by anthropogenic changes in aerosol concentrations, while rifts are due to natural variations - the origins of which are not yet known.

The major focus of this paper will be on the rift and how its microphysical and thermodynamic characteristics compare and contrast to those of the adjacent solidclouded regions, including a characterization of the variability in the microphysical characteristics and structure associated with rift areas observed in a stratocumulus deck off the coast of California. In addition, in situ data and satellite retrievals are used in tandem to further examine the microphysical differences between rifts and the surrounding cloud areas.

\section{Experiment and data}

The measurements used in this study were obtained from the Drizzle and Entrainment Cloud Study (DECS), conducted during the summer of 1999 on- and offshore of Monterey Bay, California. Data for this study of embedded rifts and gradients in stratocumulus clouds were obtained from an instrumented aircraft.

The aircraft used in this study was a Twin Otter operated by the Center for Interdisciplinary Remotely Piloted Aircraft Studies (CIRPAS) through the Naval Postgraduate School in Monterey, California, and The California Institute of Technology. The data used in this study were collected on a 16 July 1999 flight—one of several flights made from 16 June through 22 July 1999. On 16 July 1999, a rift was observed close enough to the shoreline along Monterey Bay for the Twin Otter aircraft to reach and obtain measurements of the rift and surrounding areas. This case was the only such observation of rifts within reach of the Twin Otter during the DECS experiment.

Observations taken from the Twin Otter are used to examine aerosol and microphysical properties, as well as the thermodynamic and dynamic variability of the marine boundary layer in and around the rift. These measurements include aerosol, $\mathrm{CCN}$, cloud droplet and drizzle drop concentrations, radiative fluxes, wind speeds, air temperatures, water vapor content, and sea surface temperatures. A Forward Scatter Spectrometer Probe (FSSP) measured size distributions of cloud- 
sized droplets, and a Cloud Imaging Probe (CIP) was used to measure distributions of drizzle-sized drops. Additional samplings of particle distributions were obtained from a Cloud Aerosol Spectrometer (CAS: Baumgardner et al. 2002). The CAS measures aerosols, cloud droplets, and drizzle-sized drops. For this study, the CAS probe was used to measure aerosols in the size range of $0.5-1 \mu \mathrm{m}$. CCN data were gathered using an instrument developed at Caltech and deployed successfully in several field campaigns (Chuang et al. 2000; van Reken et al. 2003). The results shown in this paper were obtained at a $0.2 \%$ supersaturation. Smaller aerosol particles were characterized using ultrafine Condensation Particle Counters (CPC) sensors operating at different supersaturation levels. Here we use the CPC to measure particles with diameters greater than $0.003 \mu \mathrm{m}$ and another CPC for diameters greater than $0.012 \mu \mathrm{m}$ to estimate ultrafine concentration in the range of 3-12 $\mathrm{nm}$. Because of the possibility of particle enhancement due to splashing on the aerosol inlet, CPC data were not analyzed when cloud droplets were observed. Further details of the instruments are provided in the appendix.

The rift observed during 16 July 1999 was located off the western coast of California, centered around $36^{\circ} \mathrm{N}$, $126^{\circ} \mathrm{W}$. The gradient area moved toward the southwest at about $10 \mathrm{~m} \mathrm{~s}^{-1}$. Figure $1 \mathrm{~b}$ shows a rough subjectively determined outline of the rift from 1700 to 2300 UTC, marking the progression of the gradient area. Through its lifetime, which in this case is about one day, the rift appears to contract in the north-south direction. Surface winds for this case were from the north-northwest below the capping inversion and west-northwest to north-northwest above it. The southward movement of the rift shown in Fig. 1b is consistent with the observed northerly winds in the boundary layer associated with low pressure inland and high pressure west of Monterey. The cellular nature of the region can also be seen in Fig. 1b. A subjective examination of this image indicates cellular structures with horizontal scales on the order of $10-20 \mathrm{~km}$.

Two types of sampling strategies were used to characterize cloud and boundary layer structure and to compare the boundary layer, cloud, and aerosol variability between the solid cloud and rift areas. A total of 19 soundings were obtained during the flight on 16 July 1999 as shown in Fig. 1b. Constant-level legs in the boundary layer were flown at four different altitudes across the northern boundary between the rift and the solid cloud.

Multispectral images from the Geostationary Operational Environmental Satellite-10 (GOES-10), available about every 15 minutes while the aircraft was flying, provided characterizations of the larger-scale cloud properties in the areas sampled by the aircraft. The GOES-10 data were analyzed with the methods of Minnis et al. $(1995,1998)$ to produce cloud macro- and microphysical properties for each pixel $(4 \mathrm{~km})$. Vertical profiles from the aircraft are classified as either solid or broken by subjective analysis of the satellite images along the flight paths. Satellite images were also used to track temporal and spatial variations in the boundary between the solid and broken clouds. In addition, satellite images were animated to track the progression of the rift. Although these images do not capture nighttime conditions very well, they clearly show the evolution of the rift during the day.

To illustrate the difference between the rift and solid cloud areas, three soundings were chosen for analysis. One was taken in a solid cloud and thus has a welldefined cloud structure that is classified as "solid deck" or "deck." Another was taken in a clear patch in the gradient area and that is designated as "clear air rift" or "rift." The third sounding was observed in a small cloud contained within the rift and is called "rift cloud." Of the 19 profiles, the average sounding took $5.5 \mathrm{~min}$ and covered an average horizontal distance approximately $19 \mathrm{~km}$, with the largest horizontal distance covered being $32 \mathrm{~km}$ and the smallest $11 \mathrm{~km}$. The three soundings analyzed in detail had an average time of 7.8 min each and an average horizontal distance of $25 \mathrm{~km}$. These soundings provide a means for comparing similarities and differences between the rift and nonrift areas.

A total of four horizontal legs of about 25-min duration were flown at heights of 100, 200, 400, and $700 \mathrm{~m}$. Data obtained on these legs were used to develop timeheight sections through the rift-nonrift boundaries. To provide these sections, a time scale for each leg was developed to give a zero point at the location where the aircraft crossed the rift boundary (the appendix). In the solid stratocumulus area, time is negative and, in the rift, time is positive for the four layers flown. There is a short gap in the data at $-5 \mathrm{~min}$. on the $200-\mathrm{m}$ flight leg due to the failure of the aircraft's data system during this time.

Downward solar radiation from the aircraft was used, in addition to the sounding location on satellite images, to further define the solid cloud-rift boundaries and the presence of cloud on each leg (Fig. 2). Along the 400-m, 200-m, and 100-m legs, there are well-defined signatures of the cloud in the downward solar flux. The downward shortwave fluxes in and below the solid stratocumulus deck were substantially reduced from those within clear areas in the rift and show relatively little variability (Fig. 2). In the rift, however, there is a welldefined clear area adjacent to the boundary with sub- 

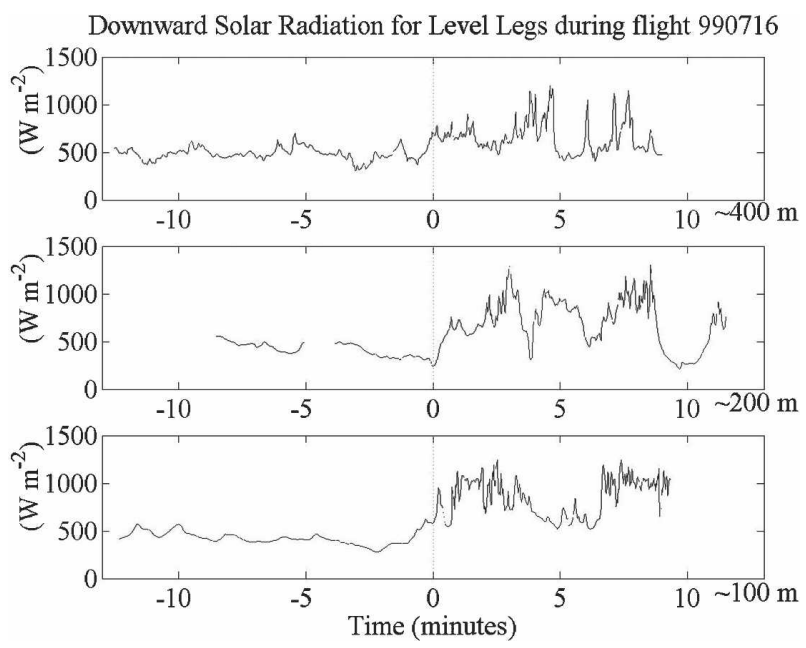

FIG. 2. Downward solar radiation measured along level legs during the flight on 16 Jul 1999. The vertical gray dashed line indicates the border between the solid stratocumulus deck and the rift region.

stantial flux variability away from the boundary. Mesoscale patches of cloud are indicated by variability in shortwave flux that is consistent with the $10-15-\mathrm{km}$ scale cellular structure observed in the satellite images.

\section{Results}

The thermodynamic structure of the boundary layer in the solid cloud deck, the clear air rift, and the rift cloud areas are similar. All show well-mixed potential temperature structure in the lower part of the boundary layer below the capping inversion (Fig. 3a). The temperatures in the solid cloud are slightly lower than those in the rift area. Inversion heights for the three soundings fall within the range from 740 to $800 \mathrm{~m}$ and are slightly higher than the $710 \pm 75 \mathrm{~m}$ average for all 19 soundings conducted during the flight. Temperatures along the level legs were averaged from $t=-1$ to -4 min in the solid deck and from $t=+1$ to +4 min in the rift to further evaluate the differences. At 200 and 400 $\mathrm{m}$, the average temperature differences between the rift and the solid deck were less than $0.1^{\circ} \mathrm{C}$. At $100 \mathrm{~m}$, the air was about $0.3^{\circ} \mathrm{C}$ cooler in the rift than in the solid deck. Potential temperature profiles above the inversion are similar for all three soundings.

Water vapor mixing ratio (Fig. 3b) also shows a fairly well mixed structure, although stratification is present at the boundary between the subcloud and cloud layers. The boundary layer mixing ratios in the solid deck are slightly lower than those in the clear air rift and the rift cloud. On the 200-m and 100-m level legs, the mixing ratios in the rift area are slightly more than $0.1 \mathrm{~g} \mathrm{~kg}^{-1}$ greater than those in the deck. The temperature and moisture differences between the rift and the deck from the level legs are not significant (the peak in water vapor mixing ratio at $720 \mathrm{~m}$ in the solid deck appears to be due to sensor wetting). Furthermore, the equivalent potential temperatures calculated from the 3-min leg averages indicate well-mixed conditions in both areas with no more than $0.3^{\circ} \mathrm{C}$ difference between the levels
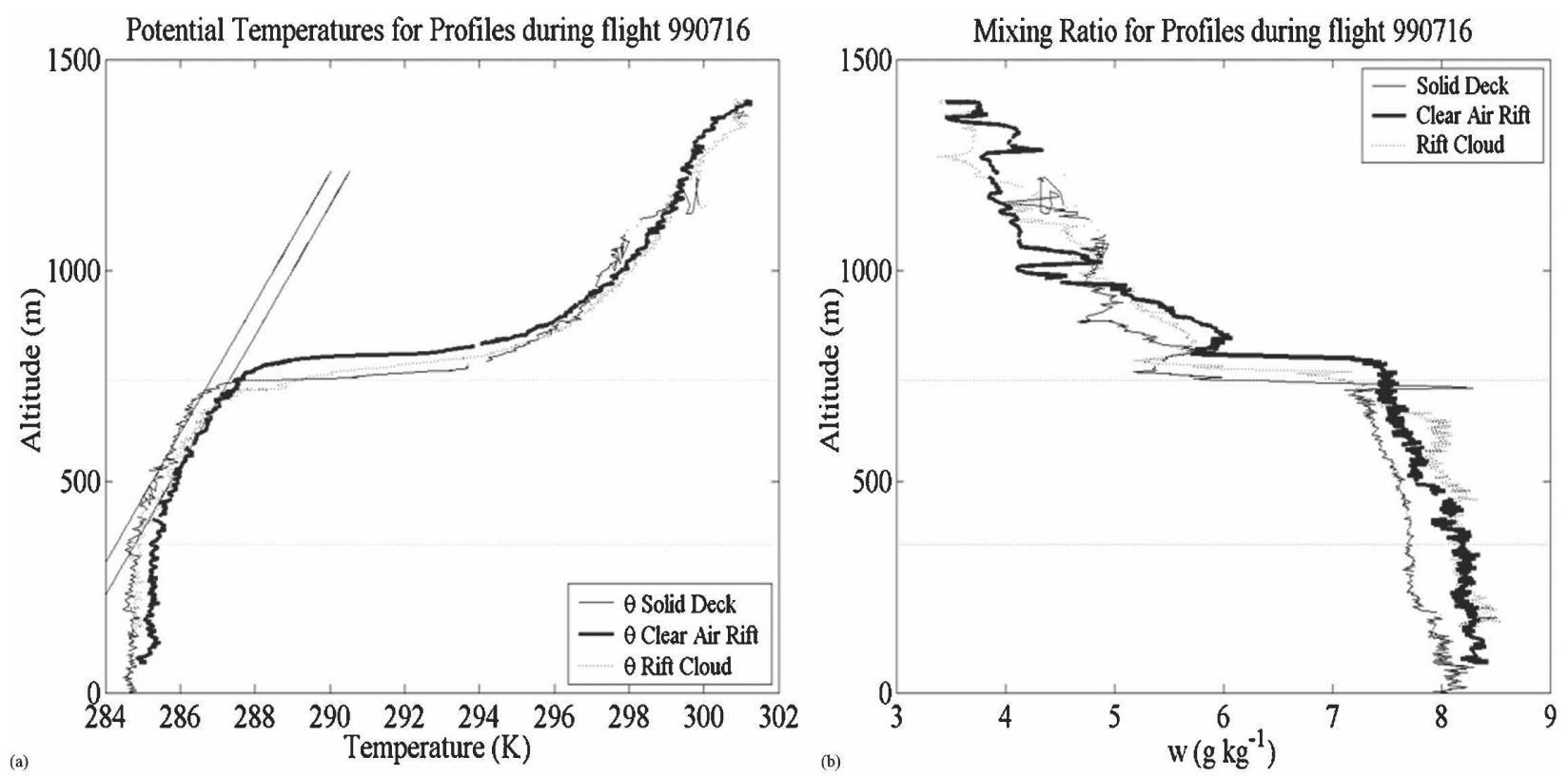

FIG. 3. (a) Potential temperature profiles for solid deck, clear air rift, and rift cloud. The black diagonal lines indicate the moist adiabatic lapse rate (MALR). (b) Mixing ratio profiles. The dashed gray lines roughly mark cloud top and cloud base of the solid cloud. 
in the solid deck and about $0.6^{\circ} \mathrm{C}$ in the rift. The moisture profiles above the inversion in the deck and the rift are similar. Thus, the moisture jumps across the capping inversion indicate that the broken nature of the clouds in the rift cannot be explained by the entrainment of dry air into the boundary layer.

Wind speeds (not shown) in the boundary layer are similar in both the rift and cloud deck area with values of about $7 \mathrm{~m} \mathrm{~s}^{-1}$ below the inversion; this speed is consistent with advection of the stratocumulus clouds and rift in the GOES-10 image (Fig. 1b). In the boundary layer, winds are from $320^{\circ}-350^{\circ}$ and shifted more westerly to about $300^{\circ}$ above the solid deck and more northerly to about $350^{\circ}$ above the clear air rift and rift cloud. Since the rift moves at about the same speed and direction as the boundary layer winds, the aboveinversion air-which is moving with a more westerly direction-does not seem to be a factor in maintaining the rift structure within the stratocumulus deck.

A hot-wire sensor measured cloud liquid water structure in the solid deck and rift cloud (Fig. 4). The profile associated with the solid stratocumulus deck shows a well-defined structure, with liquid water increasing nearly adiabatically from cloud base toward cloud top, spiking at cloud top, and then decreasing sharply above the cloud. The deviation of liquid water content from the adiabatic liquid water values near cloud top is typical of aircraft observations of marine stratocumulus (e.g., Albrecht et al. 1985) and may be due to either drizzle depletion occurring in the cloud at this level or cloud-top entrainment, which tends to enhance evaporation areas near the top of the boundary layer. The rift cloud profile indicates the presence of clouds, but the structure is not that of a classic cloud profile as observed in the solid deck. The cloud located within the rift is shallower than the solid deck cloud; the profile shows two distinct peaks centered at about 500 and 600 $\mathrm{m}$, although these peaks could be artifacts since the profiles are made as the aircraft moves horizontally; thus, the peaks may represent the sampling of two separate cloud features. Since the top of the cloud sampled is at a height below the thermal inversion, it is possible that this cloud had insufficient buoyancy to penetrate to the inversion, or was in a later stage of development with a rained-out cloud top.

The cloud droplet concentrations are substantially higher in the solid stratocumulus cloud deck than in the small rift cloud element sampled at $500 \mathrm{~m}$ (Fig. 5a). Most of these solid deck droplets are found within the cloud layer at concentrations between 40 and 60 $\mathrm{cm}^{-3}$, decreasing near cloud top. However, the average drop concentration is about $20 \mathrm{~cm}^{-3}$ in the rift

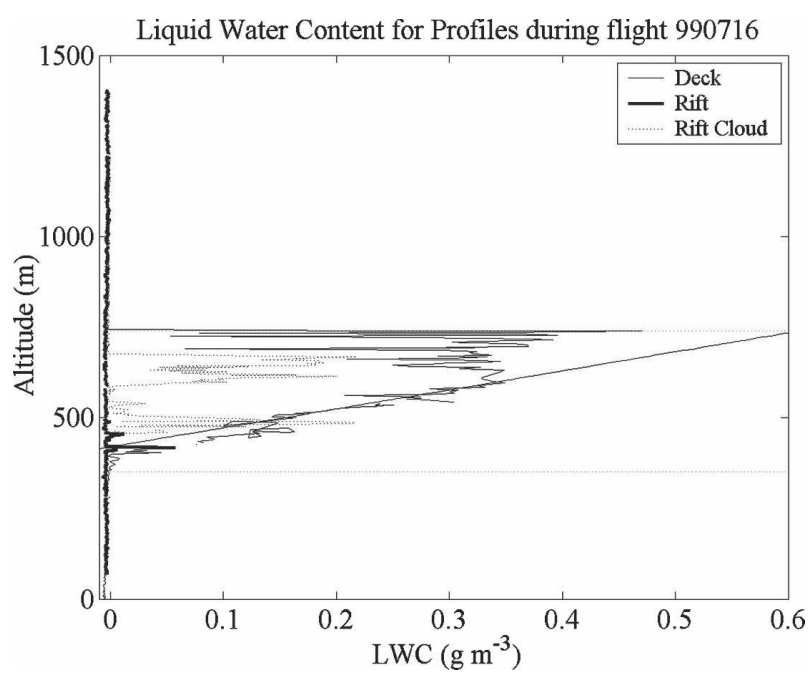

FIG. 4. Liquid water content for profiles. The horizontal dashed lines roughly mark cloud top and cloud base of the solid cloud. The gray line indicates the MALR.

cloud compared with about $40 \mathrm{~cm}^{-3}$ in the solid cloud deck.

Consistent with the locations of the largest droplet concentration, FSSP-measured effective volume diameter, or volume-weighted mean diameter, of the cloud drops increases from cloud base to cloud top in the solid deck (Fig. 5b). This increase in effective volume diameter is consistent with the increase in liquid water (Fig. 4) and a nearly constant number concentration (Fig. 5a). In the region where the concentration of droplets decreases near cloud top, the particle size increases. The rift cloud, however, does not show the same structure. Effective diameters in the rift cloud particles are slightly greater than those of the solid deck, especially in the lower cloud feature-consistent with smaller droplet concentrations in the lower cloud layer. The upper cloud feature in the rift area, however, has characteristics similar to those in the solid deck. The satellite retrievals of effective diameter discussed later, however, indicate some cloud features in the rift where there are smaller cloud droplets than those in the majority of the region. We will use these satellite observations to provide a larger-scale view of the differences in cloud properties between the two regions.

Substantial differences in drizzle characteristics are observed between the solid deck and the rift areas along the horizontal legs as shown in Fig. 6. Drizzle rates (Fig. 6a) are relatively low below the solid stratocumulus deck, although some drizzle is observed in the solid deck area adjacent to the rift boundary. In the rift area, however, drizzle rates in the range of $1-3 \mathrm{~mm}$ 

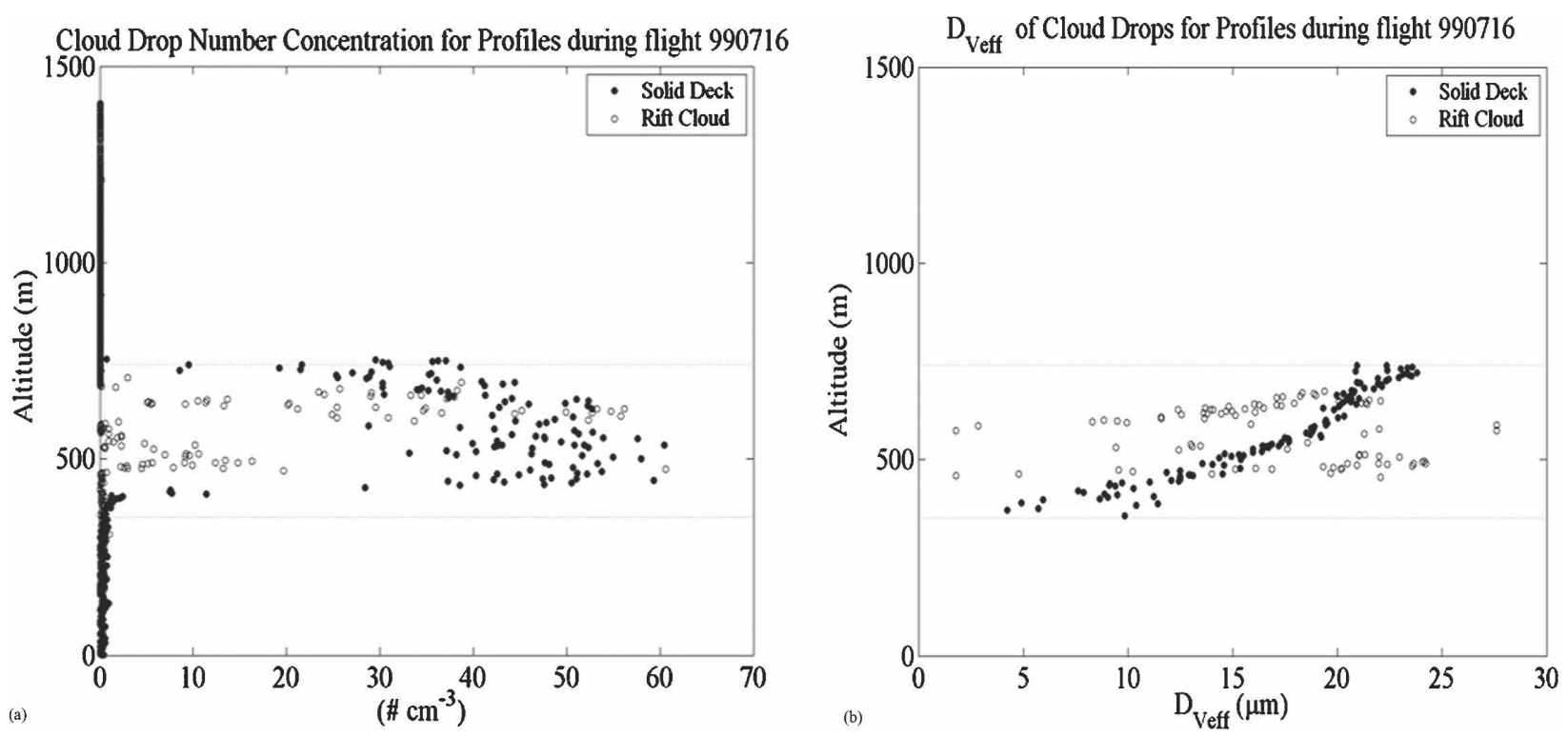

FIG. 5. (a) Cloud drop concentrations in the solid cloud and rift cloud areas. (b) Effective diameter for cloud droplets in solid cloud and rift cloud areas. The dashed gray lines roughly mark cloud top and cloud base of the solid cloud.

day $^{-1}$ are observed. The drizzle patch observed at 200 $\mathrm{m}$ within the rift (just after $t=5 \mathrm{~min}$ ) has a horizontal dimension of about $6-8 \mathrm{~km}$. The drizzle droplet effective diameters (Fig. 6b) do not vary substantially between the rift area and the solid deck adjacent to the boundary, although the rift drizzle droplets are slightly larger. This difference is consistent with the concentrations since there are relatively few, but larger, drizzle drops under the rift in the mesoscale cloud area $(t=5$ $\min )$. This concentration-size relationship is also evident at $100 \mathrm{~m}$ where slight deviations from zero in drop concentrations are associated with effective diameters of about $150 \mu \mathrm{m}$.

Precipitation rates measured on the vertical profiles show similar differences between the solid cloud and rift area (Fig. 7a). Although the drizzle rates from the rift cloud profile are higher than those observed in the solid cloud deck, the maximum rates in the rift cloud profile are about a factor of 2 smaller than the drizzle rates observed at $200 \mathrm{~m}$ on the level legs (Fig. 6a). This difference is most likely due to the limited sampling provided by the profiles made through the broken
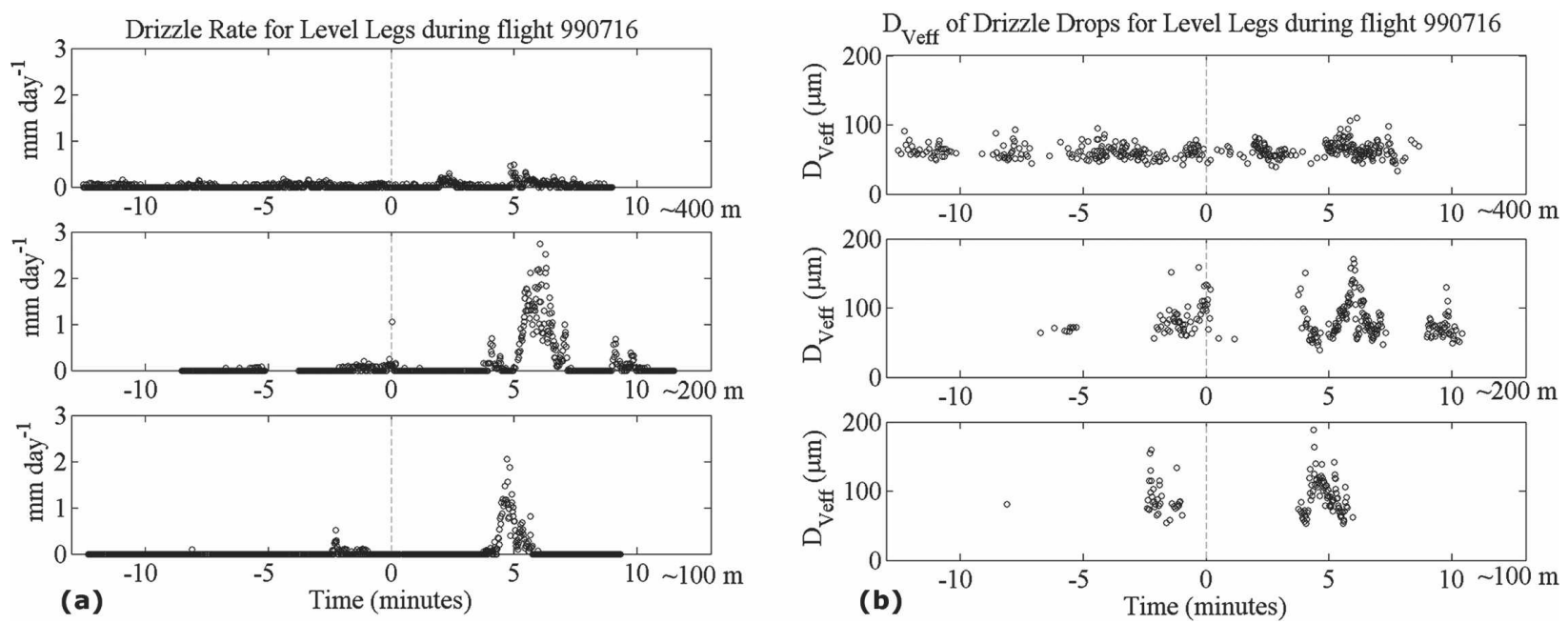

FIG. 6. (a) Drizzle rates for the horizontal legs. (b) Effective diameter for drizzle drops along the horizontal legs. The vertical gray dashed line indicates the border between the solid stratocumulus deck and rift region. 
(a)

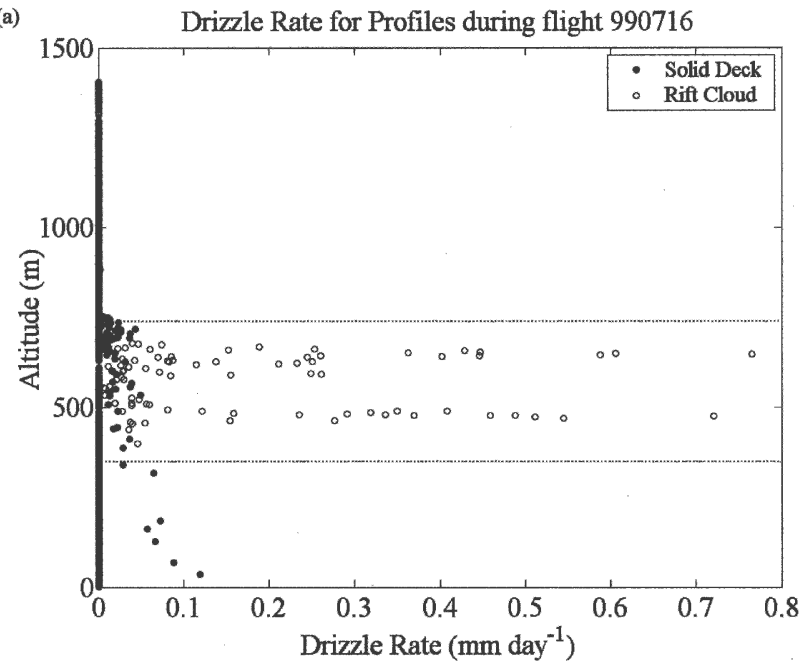

(b) $\mathrm{D}_{\text {Veff }}$ of Drizzle Drops for Profiles during flight 990716

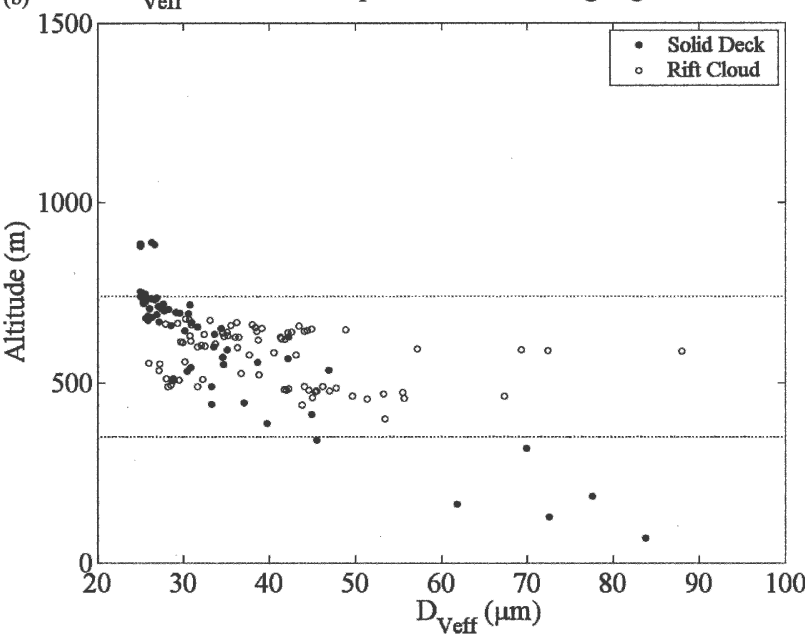

FIG. 7. (a) Drizzle rates in the solid cloud and rift cloud areas. (b) Effective diameter for drizzle drops in the cloud profiles. The horizontal dashed gray lines roughly mark cloud top and cloud base of the solid cloud.

clouds. Concentrations (not shown) of larger droplets within the deck increase near cloud top to a maximum of about $2000 \mathrm{~L}^{-1}$ with effective diameters of only 25 $35 \mu \mathrm{m}$ (Fig. 7b). These increases in drizzle concentrations near the cloud top are consistent with a well-developed cloud. The rift cloud exhibits two spikes in the same location as the liquid water content spikes of the hot-wire sensor (Fig. 4), each with concentrations just above $4000 \mathrm{~L}^{-1}$ and effective diameters of about $70-90$ $\mu \mathrm{m}$. The cloud feature near the top of the boundary layer maintains a relatively large drizzle spike despite the larger FSSP concentrations at this level than at the 400-m height.

Drop and drizzle concentration spectra obtained in the deck and the rift cloud areas are shown in Fig. 8. These spectra are from the level leg data at 400 and 200 $\mathrm{m}$. The solid deck spectra were obtained for a 0.1-min average from -0.7 to $-0.6 \mathrm{~min}$ and the rift cloud data were obtained from the cloud feature observed near $t=$ $5.5 \mathrm{~min}$ and for the period of $0.1 \mathrm{~min}$. Since $200 \mathrm{~m}$ was below cloud base, only drizzle spectra are available for this level. The spectrum for the rift cloud distinctly shows the increased drizzle contributions relative to the solid deck cloud spectra. The rift cloud drop spectrum is broader than that of the solid deck with a peak at 10.7 $\mu \mathrm{m}$ compared with $8.7 \mu \mathrm{m}$ in the solid deck. The drizzle mode is clearly enhanced in and below the rift cloud compared to the deck cloud.

$\mathrm{CCN}$ concentrations (at $0.2 \%$ supersaturation) - the most relevant quantity for cloud production-have substantial variations across the rift (Fig. 9). All of the $\mathrm{CCN}$ counts in the solid stratocumulus area $(t<0)$ are about 3 times greater than those in the rift at all levels
(Fig. 9). The lowest CCN concentrations were found near the top of the boundary layer in the clear rift area where $\mathrm{CCN}$ concentrations are near zero. Further evidence that the air sampled in this region was extremely clean will be presented in the discussion. On the other legs in and below the cloud, CCN drops markedly across the deck to rift transition. Although this air mass taken as a whole is considered "clean marine air" with

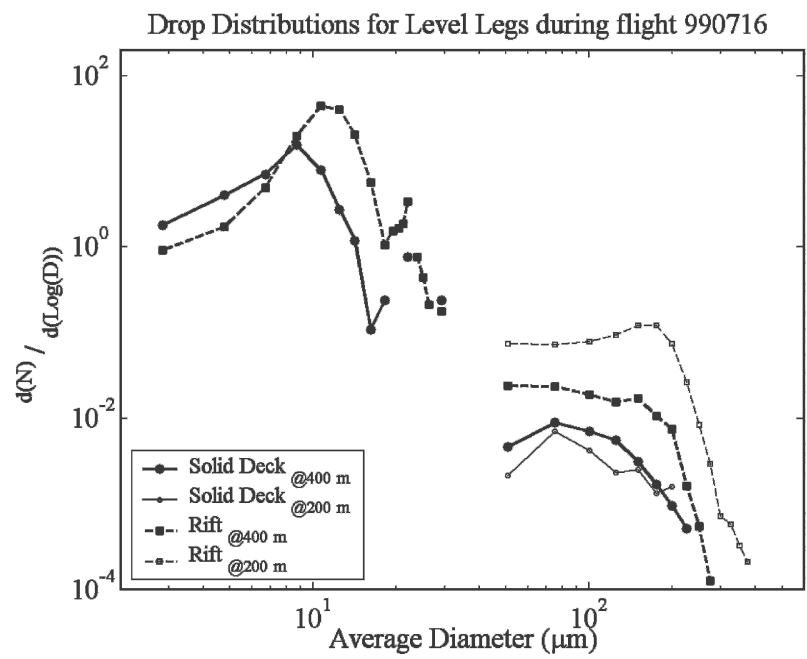

FIG. 8. Cloud and drizzle droplet spectra from the level legs in the solid cloud deck (solid line) and the rift cloud (dotted line) regions at 200 and $400 \mathrm{~m}$. These spectra are based on approximately 0.1 -min, or 6-s, averages. The cloud spectra were obtained at a height of about $400 \mathrm{~m}$. Drizzle spectra were made below the cloud (at $200 \mathrm{~m}$ ) in the two areas. The first bin of the drizzle spectra was eliminated due to instrument error of overcounting the number of droplets (thus the gap in data between the cloud and drizzle drop spectra). 


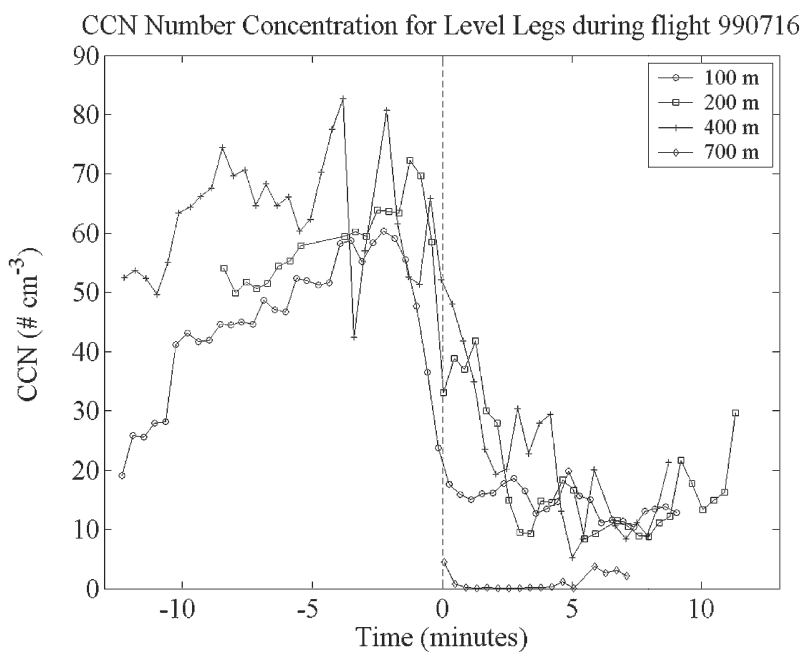

FIG. 9. CCN concentrations (at $0.2 \%$ supersaturation) for the four level legs. The vertical gray line indicates the border between the solid stratocumulus deck and rift region. Measurements made in clouds have been omitted due to instrument limitations when liquid water is present.

concentrations of $\sim 50 \mathrm{~cm}^{-3}$ of $\mathrm{CCN}$, low $\mathrm{CCN}$ concentrations of $\sim 10 \mathrm{~cm}^{-3}$ in the rift area would be considered pristine air. This variability appears to be a critical factor in creating the cloud microphysical and drizzle differences between the stratocumulus deck and embedded rift region.

Although the data are insufficient to document fully the dynamics associated with the stratocumulus deck and rift areas, microphysics seems to dominate the ob- served differences. A large-scale picture of the cloud droplet size variability is available from the satellite analyses. The radiative effective droplet diameter $D_{\text {eff }}$ was derived from the GOES-10 data using the methods of Minnis et al. $(1995,1998)$ every half hour during the flights. The method used explicitly accounts for both emitted and reflected surface contributions in broken cloud conditions. The radiative effective droplet diameter $D_{\text {eff }}$ is roughly 1.33 times greater than the volume effective diameter reported earlier. The distributions of $D_{\text {eff }}$ at both 1900 (Fig. 10a) and 2100 UTC (Fig. 10b) clearly show the rift areas as regions with $D_{\text {eff }}$ values in the range from 38 to $54 \mu \mathrm{m}$. The solid deck areas around the rift and the ship track areas within the rift typically have values of $22-30 \mu \mathrm{m}$. Figure 10 and similar images for other hours during the day indicate that much of the aircraft-sampled rift was gradually divided into smaller sections apparently as a result of the crisscrossing ship tracks that are evident as nearly linear features of reduced $D_{\text {eff }}$ in Fig. 10. Obviously, the introduction of additional aerosols from ships and from the continental air alters the microphysical structure of the rift clouds and may contribute to a reduction of drizzle, a brightening of clouds, and an increase in the cloud amount.

The in situ data show that the number of drizzle droplets increasing from the deck into the rift corresponds to a rise in $D_{\text {eff }}$. Although the values of $D_{\text {eff }}$ in the rift and in much of the solid deck area are unrealistically large, the correspondence to the in situ drizzle data suggests that $D_{\text {eff }}$ could be used as a drizzle index

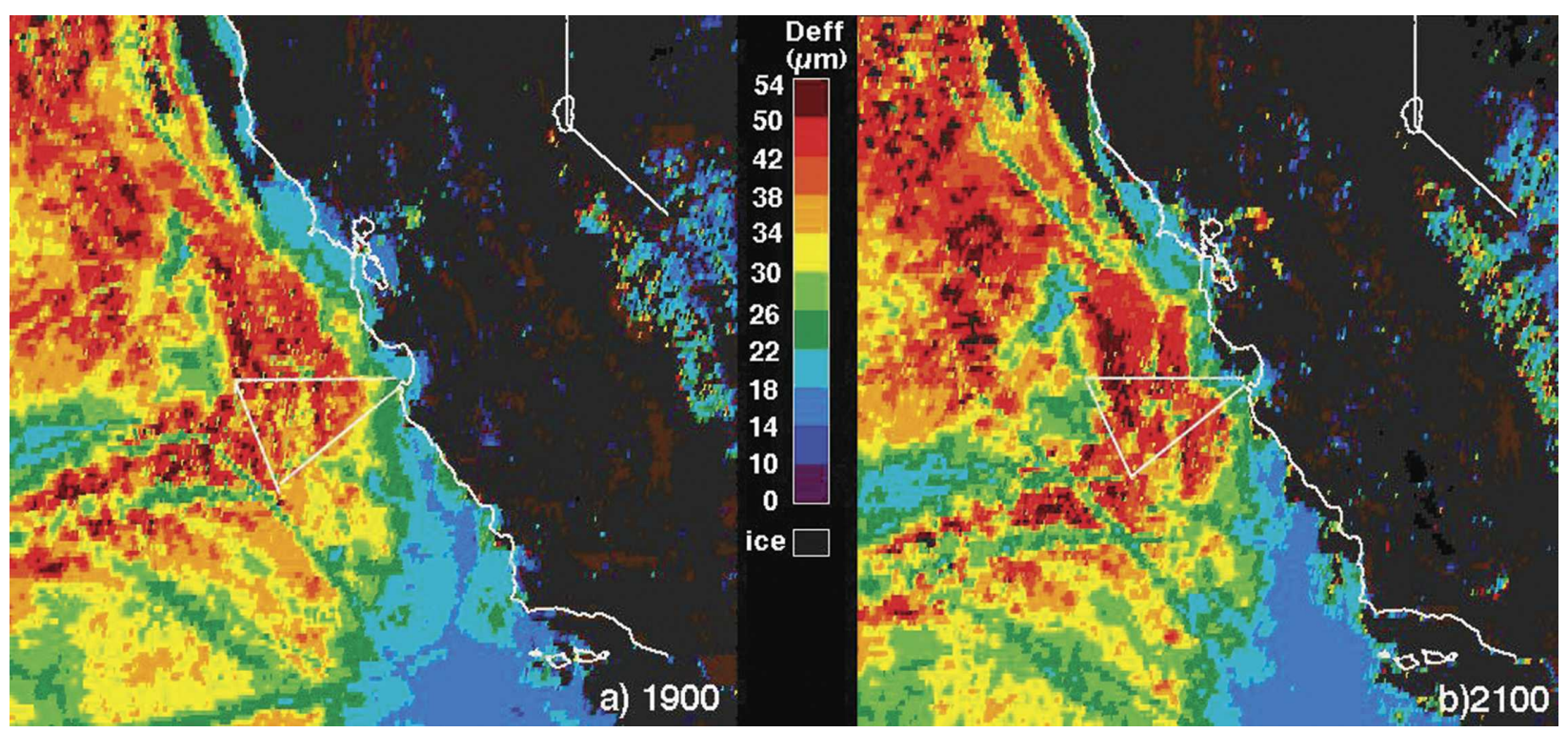

FIG. 10. Radiative effective cloud droplet diameter derived from GOES-10 data off the coast of California at (a) 1900 and (b) 2100 UTC 16 Jul 1999. 

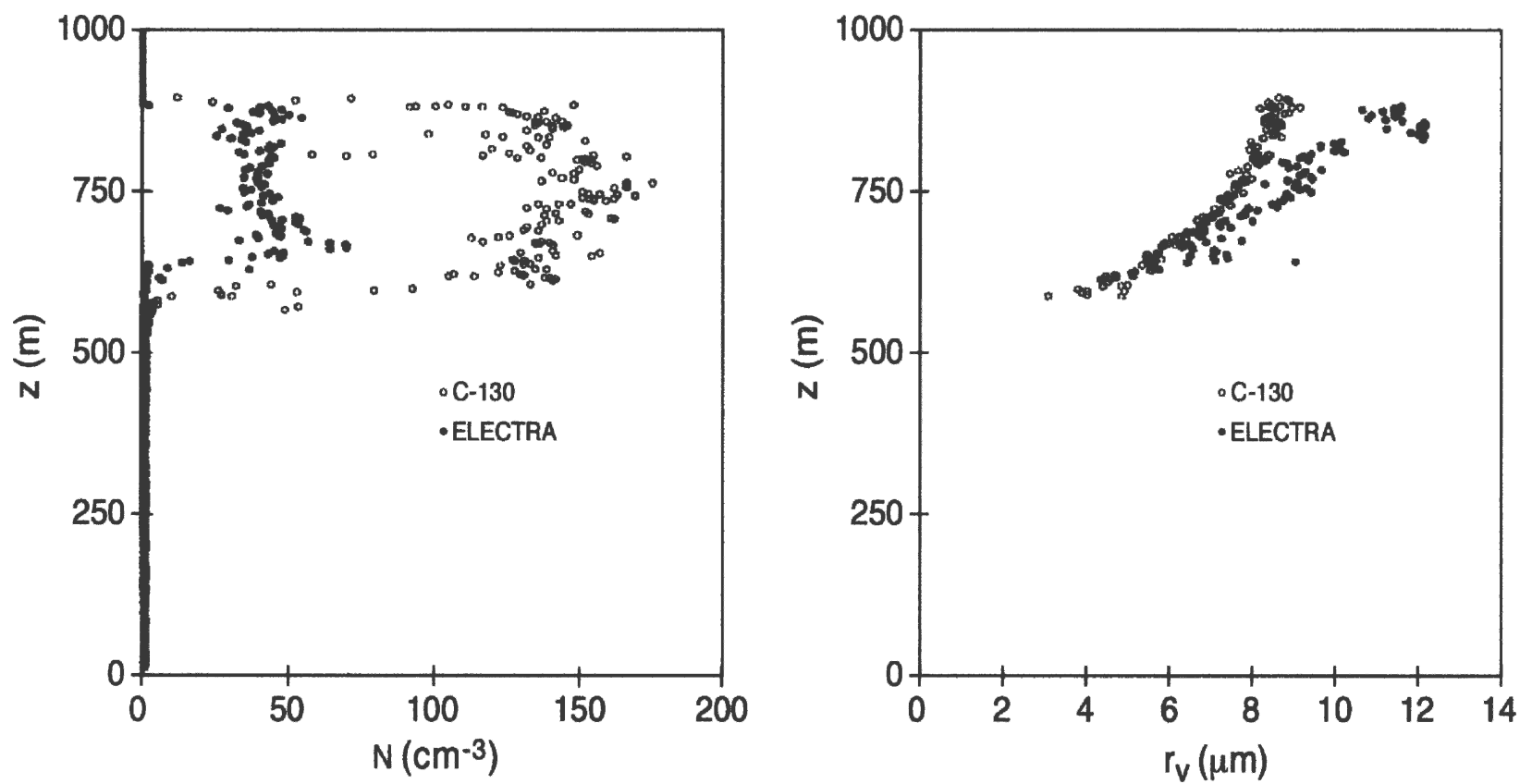

FIG. 11. Microphysical differences from the C-130 and Electra aircraft flown on 30 Jun 1987.

that would be invaluable for studying the development and filling of the rifts. Beyond that, the unique in situ data show that the droplet size distributions in these areas are broader and include more drizzle-sized droplets than the modified gamma distributions typically used for retrieving cloud droplet sizes from satellite data (e.g., Minnis et al. 1998). The added drizzle droplets, which are strong absorbers of the nearinfrared radiation used to retrieve droplet size, could explain why the retrieved values of $D_{\text {eff }}$ are so large since the satellite retrieval is sensitive to the width of the assumed droplet size distribution (Arduini et al. 2005).

\section{Discussion}

The in situ and satellite observations of the rift and deck areas indicate that the difference in the cloud characteristics between these two areas are due to aerosol and cloud microphysical differences, with little evidence that conditions at the surface or above the boundary layer were affecting these variations. Drizzle is clearly more evident in the rift clouds than the surrounding clouds. The most compelling evidence that the aerosol characteristics differ substantially between the rift and deck areas is the sharp gradient in the $\mathrm{CCN}$ concentrations across a boundary that was determined independently of these measurements.

Although there have been limited previous studies that focus on the characteristics within rift areas, a review of published studies of drizzle in marine stratocumulus clouds indicates that many of these studies were serendipitously observed in rift areas. For example, Albrecht et al. (1985) describes a broken area of stratocumulus clouds (13 June 1976) off the coast of California where drizzle was observed (Brost et al. 1982a,b). These observations were made in a low-reflectivity rift area (see Fig. 2 of Albrecht et al. 1985) and indicate cloud droplet concentrations of about $45 \mathrm{~cm}^{-3}$ compared with about $125 \mathrm{~cm}^{-3}$ observed in a solid cloud deck 4 days later during the same observational campaign.

During the First International Satellite Cloud Climatology Project (ISCCP) Regional Experiment (FIRE) in 1987, there were well-documented cases when drizzle from stratocumulus was observed (Austin et al. 1995) in clouds located off the coast of California. The clouds studied in one of these cases, 30 June 1987, are shown in Fig. 1a. On this day, the UK Met Office C-130 and the NCAR Electra flew a coordinated mission to study downstream boundary layer evolution. The C-130 and Electra were serendipitously located in adjacent areas of a solid cloud deck and a rift as shown in Fig. 1a. A detailed comparison of the thermodynamic and wind structure revealed little difference between the two areas, other than a more strongly decoupled boundary layer in the rift area than in the solid cloud. Substantial differences were observed, however, in the cloud mi- 
crophysical characteristics as shown in Fig. 11. Cloud droplet concentrations in the rift cloud were 40-50 $\mathrm{cm}^{-3}$ compared with about $150-170 \mathrm{~cm}^{-3}$ in the solid cloud. The mean volume diameter for these two regimes are about 20-22 $\mu \mathrm{m}$ in the rift cloud compared with $16 \mu \mathrm{m}$ in the solid cloud (Fig. 11). Drizzle rates were estimated to be about $0.5-1 \mathrm{~mm} \mathrm{day}^{-1}$ in the rift compared with near-zero drizzle rates in the solid cloud.

Another case of interest involves a rift area sampled by an instrumented ship in the eastern Pacific (Hindman et al. 1994). CCN concentrations measured in this area were $<10 \mathrm{~cm}^{-3}$. Although the Hindman et al. (1994) study focused on a ship trail that passed over the ship, an examination of the satellite image of this event reveals that the background for this area was a large rift. Observations from the ship indicate strong drizzle from optically thin clouds in this area (J. G. Hudson 2004, personal communication), although there is no reference to the rift area in which these measurements were made.

Stevens et al. (2005) used in situ aircraft observations with airborne lidar and radar observations to examine the structure of pockets of open cell convection (POCs). Their observations indicate enhanced drizzle within the POC compared with the surrounding cloud. Stevens et al. (2005) suggest that one possible mechanism for the formation of the POC region was enhanced water vapor above the inversion that would promote drizzle production. Further analysis of these POC areas (van Zanten and Stevens 2005; Petters et al. 2006) supports the observations of Stevens et al. (2005). The enhanced drizzle in the rift area of our study and in the FIRE study described previously does not support this hypothesis, although earlier in the history of these rifts there could have been influences from above the inversion.

The microphysical conditions documented in these previous studies are clearly consistent with those in the current study and they further support our hypothesis that drizzle processes are critical in the processing of aerosols and the maintenance of rift clouds that have low cloud droplet concentrations and a strong propensity to maintain conditions conducive to the formation of drizzle.

Although this study does not allow us to determine the origin of the rift, the satellite imagery suggests that the rift is an eroded area of a formerly continuous stratocumulus deck. It is possible that the rift originally evolved from drizzling portions of the solid deck. In the solid deck, the number of drizzle droplets is insufficient to erode the deck; but in the rift, drizzle depletes the
Ultrafine Particle Concentration for Clear Air Rift during flight 990716

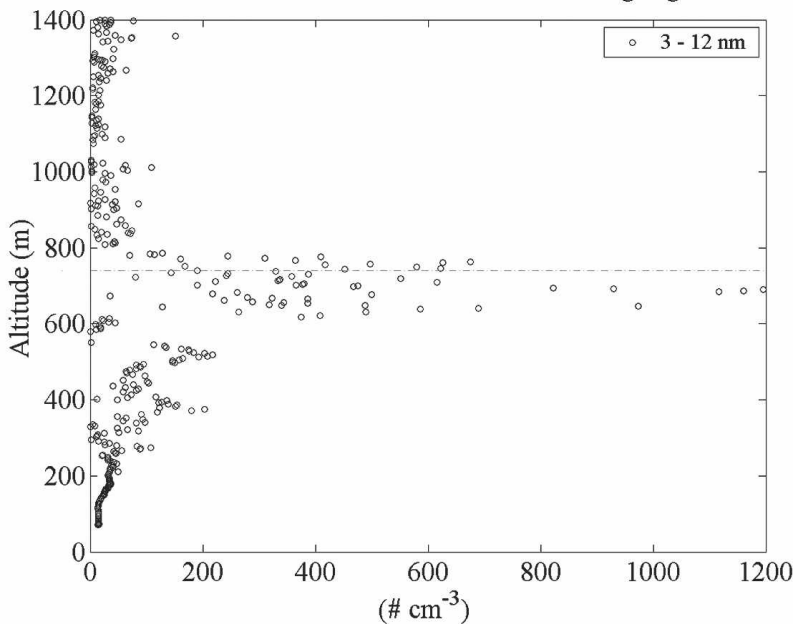

FIG. 12. Ultrafine particle concentration for the clear air rift profile. The black line indicates the average inversion height for the three profiles. Measurements made in clouds have been omitted due to instrument limitations when liquid water is present.

liquid water and inhibits the formation of a solid cloud deck while maintaining low $\mathrm{CCN}$ concentrations.

The results clearly show marked differences in the microphysical characteristics of the clouds in these two distinct stable areas, although there are no significant differences in their thermodynamic characteristics. Further, there are substantial differences in the $\mathrm{CCN}$ concentrations with remarkedly clean conditions found near the top of the boundary layer in the clear air adjacent to the solid cloud, as indicated by the lack of $\mathrm{CCN}$ at $700 \mathrm{~m}$ shown in Fig. 9. Further evidence of a patch of superclean air in this area is provided by observations of high concentrations of ultrafine particles (in the range of 3-12 $\mathrm{nm}$ ) measured by the ultrafine CPC shown in Fig. 12. Ultrafine particles are the result of homogeneous (spontaneous) nucleation that occurs in an air mass devoid of aerosols, or considered superclean air; thus, the presence of ultrafine particles indicates a region of superclean air. The profile in the clear air rift area (Fig. 12) indicates that the smallest particles have a substantial peak of about $1200 \mathrm{~cm}^{-3}$ just below the inversion in the layer from 600 to $750 \mathrm{~m}$. Further, the horizontal leg flown at $700 \mathrm{~m}$ (Fig. 13a) across the boundary also shows higher concentrations of ultrafine particles extending from the boundary at $t=0-0.5 \mathrm{~min}$. This feature has a horizontal extent of $\sim 2 \mathrm{~km}$. This area of new particle production is observed within the same area where $\mathrm{CCN}$ concentrations (Fig. 9) and aerosols in the $0.5-4.0-\mu \mathrm{m}$ range (from CAS, not shown) fall to zero. The apparent stability of these ultrafine particles is consistent with the lack of larger aerosols. If larger 
(a) Ultrafine Particle Concentration for Level Legs during flight 990716

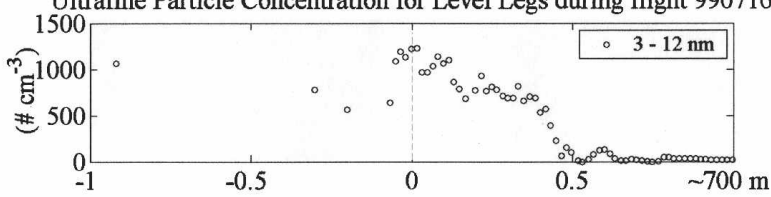

(b)

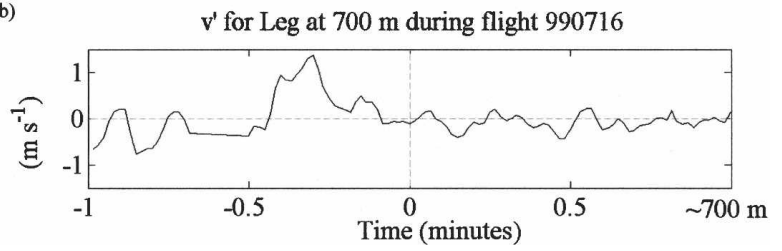

FIG. 13. (a) Ultrafine particle concentrations along the horizontal legs. Measurements made in clouds have been omitted due to instrument limitations when liquid water is present. (b) Perturbation along-wind components obtained by removing mean wind from time $t=-1.0$ to $+1.0 \mathrm{~min}$. Positive values represent an along-wind component. Here " $C$ " marks where there is alongwind convergence and " $\mathrm{D}$ " indicates where there is along-wind divergence. The vertical gray line indicates the border between the solid stratocumulus deck and rift region.

particles were present, they could provide a surface area for condensation and limit new particle formation.

Although there is little evidence of variations in the thermodynamical variables across the cloud-rift boundary, some variations in the winds were observed near the top of the inversion. To examine these variations, the winds along the 700-m flight leg were decomposed into along- and crosswind components. The along-wind (i.e., perpendicular to the deck-rift boundary) component was averaged from $t=-1.0$ to +1.0 min to give an average wind speed for this period. The deviations from this average are shown in Fig. 13b. Positive values represent an enhanced along-wind component. Thus, these perturbations indicate an area of speed convergence from $t=-0.25 \min$ to $t=0$ that is consistent with a mass transport toward the clear area boundary and subsidence near the cloud edge. A speed divergence at $t \sim-0.5 \mathrm{~min}$ is consistent with an updraft area at this point. These wind variations occur on a horizontal scale of $\sim 3.5 \mathrm{~km}$. An analysis of the wind perturbations at the lower levels indicated no detectable along-wind circulations.

These results suggest that a mesoscale circulation process may be involved in keeping air in a very pristine state in the deck-rift areas. Figure 14 provides a schematic of how such a process may work. In this idealized model, precipitation forms near the top of the solid cloud in an updraft area near the edge of the stratocumulus cloud that results in an outflow area characterized by superclean air, as indicated by reduced $\mathrm{CCN}$ concentrations and ultrafine particle production in the clear area adjacent to the deck. The subcloud inflow from the rift side into the edge of the stratocumulus deck associated with such a circulation would reduce the average number of $\mathrm{CCN}$, while providing the same amount of water vapor. These processes would tend to increase the drizzle rates at the edge of the deck and provide a mechanism for the deck to erode around the rift. In the absence of strong advective and radiative effects, the process would be self-sustaining until the deck was completely broken up. Other factors, like the diurnal cycle in solar radiation absorption that tends to dissipate the deck (e.g., Blaskovic et al. 1991), might enhance the erosion process during the day. At night, the rift should tend to fill as minimal solar absorption allows for more effective vertical mixing. Within the rift area, cumulus cells would continue to form and drizzle out in the absence of any substantial concentrations. At night the drizzle process may be enhanced as the cloud layer deepens. The removal of CCN through the drizzle process acting in the rift would maintain an environment conducive to drizzle production.

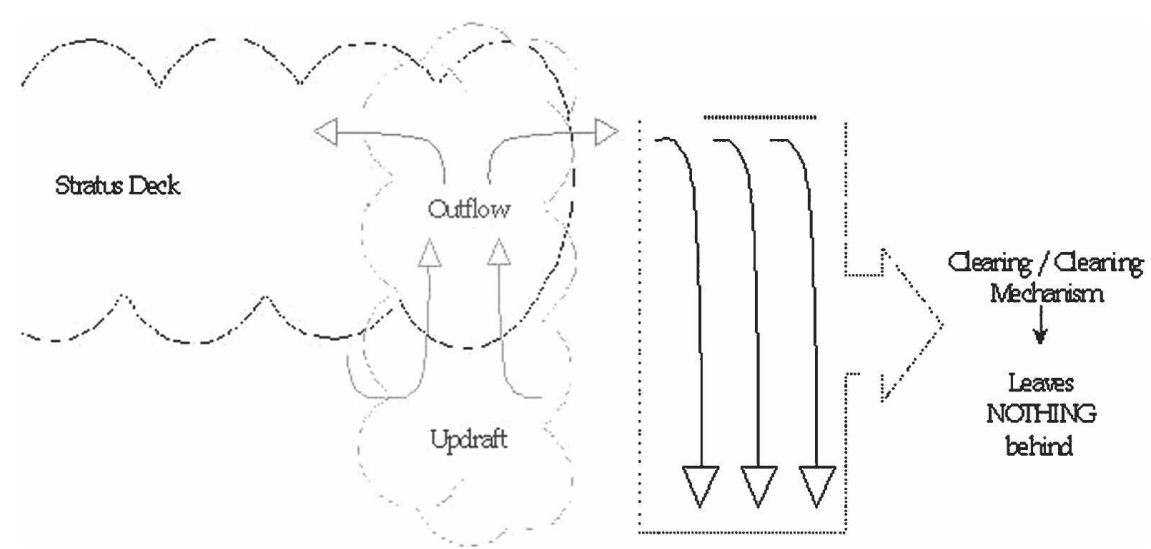

FIG. 14. Schematic of possible cleansing mechanism associated with the stratocumulus deck. 
TABLE A1. Summary of instruments used on the the CIRPAS airplane.

\begin{tabular}{ll}
\hline \multicolumn{1}{c}{ Instrument } & \multicolumn{1}{c}{ Function } \\
\hline GPS systems & Measures GPS position, speed, and altitude \\
Temperature sensor & Measures temperature with Rosemount sensor \\
Dewpoint temperature sensor & Measures dewpoint temperature with chilled mirror device \\
SST sensor & Measures sea surface temperature with TASCO sensor \\
Hot-wire liquid water content & Liquid water sensor \\
Wind, 5-hole probe & Rosemount sensor; measures true airspeed (TAS), mean wind, slip and attack angles \\
Total solar radiometer & Measures solar radiation; range 0.285-2.800 $\mu \mathrm{m}$ \\
CIP & Measures particle size distribution; used mainly for drizzle drops: $15-1550-\mu \mathrm{m}$ range \\
FSSP & Measures particle size distribution; used mainly for cloud droplets: $1.0-47.0-\mu \mathrm{m}$ range \\
CAS & Measures particle size distribution; used for particles falling within the $0.5-40-\mu \mathrm{m}$ range \\
Ultrafine CPC & Measures particle number concentration: range: $D_{p}>0.003 \mu \mathrm{m}$ \\
CCN spectrometer $(\mathrm{Cal}$ Tech) & Measures CCN; range: $0.1 \%<$ supersaturation condition $<2.0 \%$ \\
\hline
\end{tabular}

\section{Concluding remarks}

The results in this study provide evidence of indirect aerosol effects associated with natural variability in the cloud and aerosol characteristics. More specifically, these results indicate that decreases in fractional cloudiness in marine stratocumulus can be associated with high drizzle rates that maintain low $\mathrm{CCN}$ concentrations. Decreased albedos and more open cellular structures characterize the rift and gradient areas where drizzle processes work to diminish $\mathrm{CCN}$ concentrations. The ship tracks seen within the rift observed during this study indicate the susceptibility for indirect effects in rift areas. Evidence for air that has been cleansed of all CCN by cloud processes is evident in the observations presented. The presence of natural longlived variations in marine stratocumulus cloud associated with the naturally forming rift areas and humaninduced ship tracks clearly supports the theory of bistable CCN and cloud states (Baker and Charlson 1989) and provides convincing evidence in support of the mechanisms responsible for the second aerosol indirect effect. A review of results from previous studies indicates similar microphysical characteristics in rift features that were sampled serendipitously.

Since cloud rifts can affect widespread areas of the earth's extensive stratocumulus decks, it is important to understand the physical mechanisms that initiate these areas, since these mechanisms may be closely tied to other components of the climate system. A relatively simple mechanism has been proposed here for maintaining a rift, but the perturbation that initiates a rift or the conditions that lead to the filling of a rift remains undetermined. Further study is required to fully understand the marine stratocumulus rift areas. In addition to testing the hypothesis for rift maintenance, such future studies should include research on the formation of rift regimes as well as dissipation of rifts to determine how they form and why they dissipate. A complete understanding of the processes maintaining and dissipating the marine stratocumulus decks requires knowledge of the large-scale context, which is only available from satellite data. The development of improved satellite algorithms for quantifying drizzle in conjunction with other cloud characteristics is needed along with in situ data and detailed cloud process models. In addition to tracking long-lived rifts, satellite observations should provide a more global perspective on the frequency of rift occurrence, the extent of their influence, and their macroscopic characteristics and variability. That information together with more detailed in situ data is needed to realistically account for rifts in marine stratocumulus clouds and studying aerosol, cloud, and drizzle interactions due to natural processes.

Acknowledgments. This research was supported under NSF Grant ATM-9902416. The efforts of Dr. Phil Durkee in directing the aircraft to the rift area studied are greatly appreciated. Hal Maring is thanked for his valuable assistance with the interpretation of the new particle production. Additionally, we wish to thank Kirk Ayers for assistance with analyzing the satellite data. The satellite analyses were supported by NOAA CooperativeAgreement NA00AABRG0330 under the PACS Program and the Environmental Sciences Division of the U.S. Department of Energy through the Interagency Cooperative Agreement DE-AI02-97ER62341.

\section{APPENDIX}

\section{Instrumentation and Data Analysis Details}

\section{a. Instrumentation}

A detailed description of the instruments used on the CIRPAS Twin Otter is given in Table A1. (Further 
TABLE A2. Summary of time and transformation of time for level legs.

\begin{tabular}{lllll}
\hline \hline & \multicolumn{3}{c}{ Leg at } \\
\cline { 2 - 4 } & \multicolumn{1}{c}{$100 \mathrm{~m}$} & $200 \mathrm{~m}$ & $400 \mathrm{~m}$ & $700 \mathrm{~m}$ \\
\hline Time at start of leg & $\sim 1924$ UTC & $\sim 2004 \mathrm{UTC}$ & $\sim 2027 \mathrm{UTC}$ & $\sim 2052 \mathrm{UTC}$ \\
Time at border & $\sim 1937$ UTC & $\sim 2016 \mathrm{UTC}$ & $\sim 2038 \mathrm{UTC}$ & $\sim 2102 \mathrm{UTC}$ \\
Mission time at start & $8860 \mathrm{~s}$ & $11260 \mathrm{~s}$ & $12660 \mathrm{~s}$ & $14160 \mathrm{~s}$ \\
Modification of time & Leg $-9600 \mathrm{~s}$ & $11950 \mathrm{~s}-$ leg & Leg $-13300 \mathrm{~s}$ & $14770 \mathrm{~s}-1$ leg \\
\hline
\end{tabular}

details about the instruments on board the aircraft can be found online at http://web.nps.navy.mil/ cirpas/.) Expected precision and accuracy for the instruments do not represent possible errors due to instrument wetting or artifacts caused by operation from a moving platform. The relatively slow airspeed of the Twin Otter minimizes errors often found under high-speed conditions. Wetting of the sensor is minimized by the use of appropriate housings. Examination of the temperatures obtained in clouds shows little evidence of wetting problems with good agreement between the temperature and the dewpoint measurements in cloud. Some evidence of wetting of the humidity sensor is indicated by higher humidities near cloud top during an ascending sounding from the aircraft. Instruments were calibrated before and after the experiment. Details of the CCN counter can be found in Chuang et al. 2000.

\section{b. Transformed time scale}

The time for each of the horizontal legs that crossed the deck-rift boundary was transformed to give a time scale such that the border was specified as the zero point $(t=0)$. Further, the modified time to the left of the border $(t<0)$ marked the area associated with the solid deck and time to the right of the boundary $(t>0)$ is associated with the rift region. The corresponding flight times associated with this transformed time scale are given in Table A2.

\section{REFERENCES}

Albrecht, B. A., 1989: Aerosols, cloud microphysics, and fractional cloudiness. Science, 245, 1227-1230.

—, R. S. Penc, and W. S. Schubert, 1985: An observational study of cloud-topped mixed layers. J. Atmos. Sci., 42, 800 822.

Arduini, R. F., P. Minnis, and J. K. Ayers, 2005: Sensitivity of satellite-derived cloud properties to the effective variance of cloud droplet size distribution. Proc. 15th ARM Science Team Meeting, Daytona Beach, FL, 13 pp. [Available online at http://www.arm.gov/publications/proceedings/conf15/ extended_abs/arduini_rf.pdf.]

Austin, P., Y. Wang, V. Kujala, and R. Pincus, 1995: Precipitation in stratocumulus clouds: Observational and modeling results. J. Atmos. Sci., 52, 2329-2352.
Baker, M. B., and R. J. Charlson, 1989: Bistability in CCN concentrations and thermodynamics in the cloud-topped boundary layer. Nature, 345, 142-144.

Baumgardner, D. H., H. Jonsson, W. Dawson, D. O'Commor, and R. Newton, 2002: The cloud aerosol and precipitation spectrometer (CAPS): A new instrument for cloud investigations. Atmos. Res., 59-60, 251-264.

Blaskovic, M., R. Davies, and J. B. Snider, 1991: Diurnal variation of marine stratocumulus over San Nicolas Island during July 1987. Mon. Wea. Rev., 119, 1469-1478.

Brost, R. A., D. H. Lenschow, and J. C. Wyngaard, 1982a: Marine stratocumulus layers. Part I: Mean conditions. J. Atmos. Sci., 39, 800-817.

— J. C. Wyngaard, and D. H. Lenschow, 1982b: Marine stratocumulus layers. Part II: Turbulence budgets. J. Atmos. Sci., 39, 818-836.

Chuang, P. Y., A. Nenes, J. N. Smith, R. C. Flagan, and J. H. Seinfeld, 2000: Design of a CCN instrument for airborne measurement. J. Atmos. Oceanic Technol., 17, 1005-1019.

Durkee, P. A., and Coauthors, 2000a: Composite ship track characteristics. J. Atmos. Sci., 57, 2542-2553.

— K. K. Noone, and R. T. Bluth, 2000b: The Monterey Area Ship Track experiment. J. Atmos. Sci., 57, 2523-2541.

Ferek, R. J., and Coauthors, 2000: Drizzle suppression in ship tracks. J. Atmos. Sci., 57, 2707-2728.

Hegg, D. A., 1999: Dependence of marine stratocumulus formation on aerosols. Geophys. Res. Lett., 26, 1429-1432.

Hindman, E. E., W. M. Porch, J. G. Hudson, and P. A. Durkee, 1994: Ship-produced cloud lines of 13 July 1991. Atmos. Environ., 28, 3393-3403.

Hobbs, P. V., and Coauthors, 2000: Emissions from ships with respect to their effects on clouds. J. Atmos. Sci., 57, 25702590 .

Hoppel, W. A., J. W. Fitzgerald, G. M. Frick, R. E. Larson, and E. J. Mack, 1990: Aerosol size distributions and optical properties found in the marine boundary layer over the Atlantic Ocean. J. Geophys. Res., 95, 3659-3686.

Hudson, J. G., and S. S. Yum, 1997: Droplet spectral broadening in marine stratus. J. Atmos. Sci., 54, 2642-2654.

Klein, S. A., D. L. Hartman, and J. R. Norris, 1995: On the relationships among low-cloud structure, sea surface temperature, and atmospheric circulation in the summertime northeast Pacific. J. Climate, 8, 1140-1155.

Minnis, P., and Coauthors, 1995: Cloud optical property retrieval (Subsystem 4.3). Clouds and the Earth's Radiant Energy System (CERES) Algorithm Theoretical Basis Document. Vol. III: Cloud analyses and radiance inversions (Subsystem 4). NASA Rep. 1376, Vol. 3, CERES Science Team, CERES, 135-176.

, D. P. Garber, D. F. Young, R. F. Arduini, and Y. Takano, 
1998: Parameterization of reflectance and effective emittance for satellite remote sensing of cloud properties. J. Atmos. Sci., 55, 3313-3339.

Petters, M. D., J. R. Snider, B. Stevens, G. Vali, I. Faloona, and L. Russell, 2006: Accumulation mode aerosol, pockets of open cells, and particle nucleation in the remote subtropical Pacific marine boundary layer. J. Geophys. Res., 111, D02206, doi:10.1029/2004JD005694.

Stevens, B., G. Vali, K. Comstock, R. Wood, M. C. van Zanten, P. H. Austin, C. S. Bretherton, and D. H. Lenschow, 2005: Pockets of open cells (POCs) and drizzle in marine stratocumulus. Bull. Amer. Meteor. Soc., 86, 51-57.
Twomey, S., 1974: Pollution and the planetary albedo. Atmos. Environ., 8, 1251-1256.

- 1977: The influence of pollution on the shortwave albedo of clouds. J. Atmos. Sci., 34, 1149-1152.

van Reken, T. M., T. A. Rissman, G. C. Roberts, V. Varutbangkul, H. H. Jonsson, R. C. Flagan, and J. H. Seinfeld, 2003: Toward aerosol/cloud condensation nucleus (CCN) closure during CRYSTAL-FACE. J. Geophys. Res., 108, 4633, doi:10.1029/2003JD003582.

van Zanten, M. C., and B. Stevens, 2005: Observations of the structure of heavily precipitating marine stratocumulus. J. Atmos. Sci., 62, 4327-4342. 